\title{
Role of the Phytochemicals from the Cocoa Shell on the Prevention of Metabolic Syndrome by an Integrated Network Pharmacology Analysis ${ }^{+}$
}

\author{
Miguel Rebollo-Hernanz ${ }^{1,2, *(D)}$, Silvia Cañas ${ }^{1,2} \mathbb{D}$, Cheyenne Braojos ${ }^{1,2}$, Silvia M. Arribas ${ }^{3}$ \\ and Maria A. Martin-Cabrejas 1,2 (D)
}

1 Department of Agricultural Chemistry and Food Science, Universidad Autónoma de Madrid, 28049 Madrid, Spain; silvia.cannas@uam.es (S.C.); cheyenne.barojos@uam.es (C.B.); maria.martin@uam.es (M.A.M.-C.)

2 Institute of Food Science Research, CIAL (UAM-CSIC), 28049 Madrid, Spain

3 Department of Physiology, Universidad Autónoma de Madrid, 28029 Madrid, Spain; silvia.arribas@uam.es

* Correspondence: miguel.rebollo@uam.es

+ Presented at the 1st International Electronic Conference on Biomedicine, 1-26 June 2021; Available online: https:/ / ecb2021.sciforum.net/.

Citation: Rebollo-Hernanz, M.; Cañas, S.; Braojos, C.; Arribas, S.M.; Martin-Cabrejas, M.A. Role of the

Phytochemicals from the Cocoa Shell on the Prevention of Metabolic

Syndrome by an Integrated Network Pharmacology Analysis. Biol. Life Sci. Forum 2021, 7, 15. https://doi.org/ 10.3390/ECB2021-10256

Academic Editor: Ciro Isidoro

Published: 31 May 2021

Publisher's Note: MDPI stays neutral with regard to jurisdictional claims in published maps and institutional affiliations.

Copyright: (c) 2021 by the authors Licensee MDPI, Basel, Switzerland. This article is an open access article distributed under the terms and conditions of the Creative Commons Attribution (CC BY) license (https:// creativecommons.org/licenses/by/ $4.0 /)$.

\begin{abstract}
The metabolic syndrome is a cluster of conditions that occur together, increasing the risk of chronic diseases such as obesity, type II diabetes, or cardiovascular disease. Nutritional interventions improving inflammation, bioenergetics, and oxidative stress are proposed as effective tools in preventing metabolic syndrome. The cocoa shell is a by-product generated in large amounts during cocoa production. This by-product contains alkaloids and phenolic compounds as main compounds and has been investigated as an anti-obesity and anti-diabetic agent. Here, we used network pharmacology to explore the potential mechanism of the phytochemicals from the cocoa shell. We searched the cocoa shell's phytochemical composition; then, oral bioavailability and druglikeness were screened. We predicted the targets for the phytochemicals found in this by-product and used different databases to search for compound-protein and compound-gene interactions, and then protein-protein interaction networks were constructed. Moreover, pathway enrichment analysis was performed, and biological processes and signaling pathways were identified and illustrated through bioinformatics analyses. Theobromine, caffeine, procyanidin B2, (-)-epicatechin, $(+)$-catechin, and protocatechuic acid were identified in the cocoa shell as main components. Those phytochemicals were associated with inflammation (TNF- $\alpha$, NF- $k B, J N K)-$, oxidative stress (CAT, SOD)-, obesity (adiponectin, leptin, FASN, PPAR- $\alpha$ )-, and diabetes (insulin, AKT)-related pathways. Results demonstrated that cocoa shell phytochemicals could modulate multiple biological processes and signaling pathways in a multimechanistic manner. Hence, cocoa shell consumption could support the nutritional prevention of metabolic syndrome. Future in vivo and clinical investigations will be needed to validate this potential nutraceutical and healthy ingredient's effects and mechanisms.
\end{abstract}

Keywords: metabolic syndrome; obesity; diabetes; cardiovascular disease; cardiometabolic disease; inflammation; oxidative stress; cocoa shell; cocoa by-products; phytochemicals; theobromine; caffeine; phenolic compounds; network pharmacology; bioinformatic analysis; signaling pathway

\section{Introduction}

Metabolic syndrome is a group of clinical conditions and disorders, including obesity, insulin resistance, glucose intolerance, hypertension, and dyslipidemia, increasing the risk of cardiovascular disease [1]. The incidence of metabolic syndrome has risen in recent years, especially in developed countries, but there is currently no treatment [2]. Therapeutic strategies to prevent or reduce the consequences of these disorders are mainly based on diet and physical activity. In recent years, research has focused on exploring and using bioactive compounds with beneficial properties to handle chronic metabolic diseases [3]. Phenolic 
compounds and alkaloids are of particular interest among these bioactive compounds, which have been related to the prevention of diseases such as diabetes, obesity, or cancer, and exert neuroprotective, anti-inflammatory, and anti-hypertensive effects [3,4].

The cocoa shell is a by-product obtained from the cocoa industry during the processing of cocoa beans. This by-product is removed from the outer portions of beans after the roasting process [5]. In cocoa production, the cocoa shell is considerable, representing $10-20 \%$ of the cocoa bean $[6,7]$. The cocoa shell is composed mainly of carbohydrates $(7.8-70.2 \%)$, dietary fiber $(39.2-66.3 \%)$, protein $(10.3-27.4 \%)$, and fat $(1.5-8.5 \%)$. The cocoa shell also contains other minority compounds such as polyphenols $(0.3-9.5 \%)$ and methylxanthines such as theobromine (0.4-1.8\%) and caffeine (0.1-0.4\%) [8]. Due to its high content of dietary fiber and valuable bioactive compounds (phenolic compounds and methylxanthines), the cocoa shell could be used as a new food ingredient with valuable potential in treating metabolic syndrome $[9,10]$.

Network pharmacology is a new discipline that aims to understand the actions and interactions of drugs with multiple targets. This discipline is gaining popularity as a new tool in drug discovery for its cost-effectiveness as it uses in silico data and its good predictability. Network pharmacology combines multidisciplinary technologies, such as systems biology and computational biology, to build a complex network between phytochemicals and target disease biomarkers and elucidate the mechanism of active compounds in disease prevention [11,12]. Thus, this study aimed to investigate the cocoa shell's phytochemical composition and find the potential biological effects of its main components in preventing metabolic syndrome by using an integrated network pharmacology approach.

\section{Materials and Methods}

\subsection{Phytochemicals Collection and Screening}

The phytochemicals found in the cocoa shell were extracted from the literature through a wide-scale text-mining method.

\subsection{ADME Screening}

In silico methods for identifying the pharmacokinetics of the phytochemicals found in the cocoa shell were an effective approach for filtering among all active components. We employed two ADME parameters, including drug-likeness (DL) and oral bioavailability $(\mathrm{OB})$, generated by three in silico ADME models. The compounds which successfully satisfy the criteria: $\mathrm{DL} \geq 0.18$ and $\mathrm{OB} \geq 35 \%$ were treated as candidate compounds.

\subsection{Target Fishing and Network Construction}

\subsubsection{Target Acquisition for Phytochemicals and Disease-Related Effects}

Metabolic syndrome-related genes were searched and screened by the following electronic databases: GeneCard database (https: / /www.genecards.org/ (accessed on 21 May 2021)), OMIM database (https:/ /www.omim.org/ (accessed on 21 May 2021)), PharmGkb database (https:/ / www.pharmgkb.org/ (accessed on 21 May 2021)), Therapeutic Targets database (http:/ / bidd.nus.edu.sg/BIDD-Databases/TTD/TTD.asp (accessed on 21 May 2021)), and DrugBank database (https:/ / www.drugbank.ca (accessed on 21 May 2021)). The database search results were combined, and duplicate targets were deleted to obtain all the targets for preventing metabolic syndrome.

\subsubsection{Construction of Active Phytochemicals and Disease Target Network}

The screening results of the active phytochemicals of the cocoa shell in metabolic syndrome targets were imported into Cytoscape, and an interactive network was constructed. 
2.3.3. Mechanism of Action Predicted for Major Phytochemicals in the Cocoa Shell

The mechanism of action of major compounds in the cocoa shell was predicted using Prediction of Activity Spectra for Substances (PASS). This tool provides quantitative structure-activity relationships containing $>205,000$ compounds based on the chemical structures in 2D and 3D descriptors and the generation of models obtained from bioactive ligands [13].

\subsubsection{Protein-protein Interaction Network and Enrichment Analysis}

Protein-protein interaction networks and enrichment analysis were carried out using Metascape. Each gene was studied for its pathway and process enrichment score for statistical significance of genes in each biological process. Genes were also clustered according to their pathways. The relationship between genes was also identified using the network map generated from the Metascape tool and visualized in the Cytoscape tool.

\subsection{Statistical Analysis}

The results were reported as the mean \pm standard deviation (SD) $(n=3)$ and analyzed using one-way ANOVA and the post hoc Tukey test. Differences were considered significant at $p<0.05$.

\section{Results and Discussion}

3.1. Methylxanthines and Phenolic Compounds Are the Main Phytochemicals Found in the Cocoa Shell: The Biological Activity Is Limited to their Different Bioavailability

The main phytochemicals found in cocoa shells (Figure 1A) were methylxanthines (theobromine $(\mathrm{TH})$ and caffeine (CAF)) and phenolic compounds (protocatechuic acid (PCA), procyanidin B2 (PB2), (-)-epicatechin (EPI), and (+)-catechin (CAT)) [14]. According to the ADMET predictions, CAF was the compound showing the highest bioavailability (79.6\%), followed by TH, CAT, EPI, PCA $(65.7 \%, 62.8 \%, 54.2 \%, 49.1 \%$, respectively), although not showing significant $(p>0.05)$ differences among them. However, the compound with the lowest $(p<0.05)$ bioavailability was PB2 $(36.2 \%)$. The bioavailability of phytochemicals is crucial to ensure these compounds' bioefficacy in modulating metabolic targets [15]; therefore, these six phytochemicals seem to be potential nutraceuticals candidates.

\subsection{Phenolic Compounds from the Cocoa Shell Exhibit Reactive Oxygen Species (ROS) Scavenging Properties and Regulates Oxidative Stress-Related Pathways}

Phenolic compounds present in cocoa shells showed ROS scavenging properties (Figure 1C). PB2, EPI and CAT exhibited the highest $(p<0.05)$ ROS scavenging values $(79.8-84.2 \%)$. PCA presented a significantly $(p<0.05)$ lower ROS scavenging $(54.6 \%)$ compared with the other phenolic compounds. Phenolic compounds, because of their structure, have the ability to interact with ROS, preventing cell viability from being affected [16] The enzyme NADPH oxidase (NOX) (Figure 1D), whose only function is to produce ROS can be inhibited according to PASS predictions by PCA, EPI, and CAT (61.9-85.2\%). PB2, $\mathrm{TH}$, and CAF (52.4-61.1\%) were also able to inhibit NOX to a lesser $(p<0.05)$ degree. Phenolic compounds have an inhibitory effect on NOX enzyme activity, which may be a good strategy to combat oxidative stress [17]. Similarly, phytochemicals in the cocoa shell present the potential ability to stimulate antioxidant enzymes, such as SOD (10.2-43.6\%) and CAT (13.1-52.3\%). Recently, several studies have demonstrated the ability of cocoa shell extracts rich in phenolic compounds in the prevention of ROS production $[9,10,18]$. 
A<smiles></smiles><smiles>Cn1c(=O)c2ncn(C)c2n(C)c1=O</smiles><smiles>O=C(O)c1ccc(O)c(O)c1</smiles>

Theobromine $(\mathrm{TH})$

Caffeine (CAF)

Protocatechuic acid (PCA)<smiles>Oc1cc(O)c2c(c1)O[C@H](c1ccc(O)c(O)c1)CC2O</smiles>

(-)-Epicatechin (EPI)

B

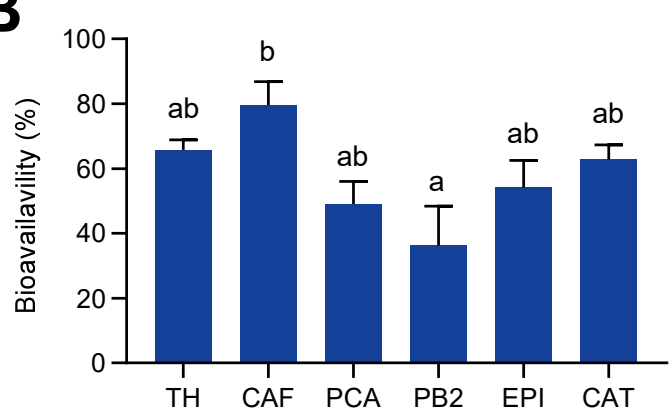<smiles>Oc1cc(O)c2c(c1)O[C@H](c1ccc(O)c(O)c1)[C@H](O)C2c1c(O)cc(O)c2c1O[C@H](c1ccc(O)c(O)c1)[C@H](O)C2</smiles>

Procyanidin B2 (PB2)<smiles>Oc1cc(O)c2c(c1)O[C@H](c1ccc(O)c(O)c1)[C@H](O)C2</smiles>

(+)-Catechin (CAT)
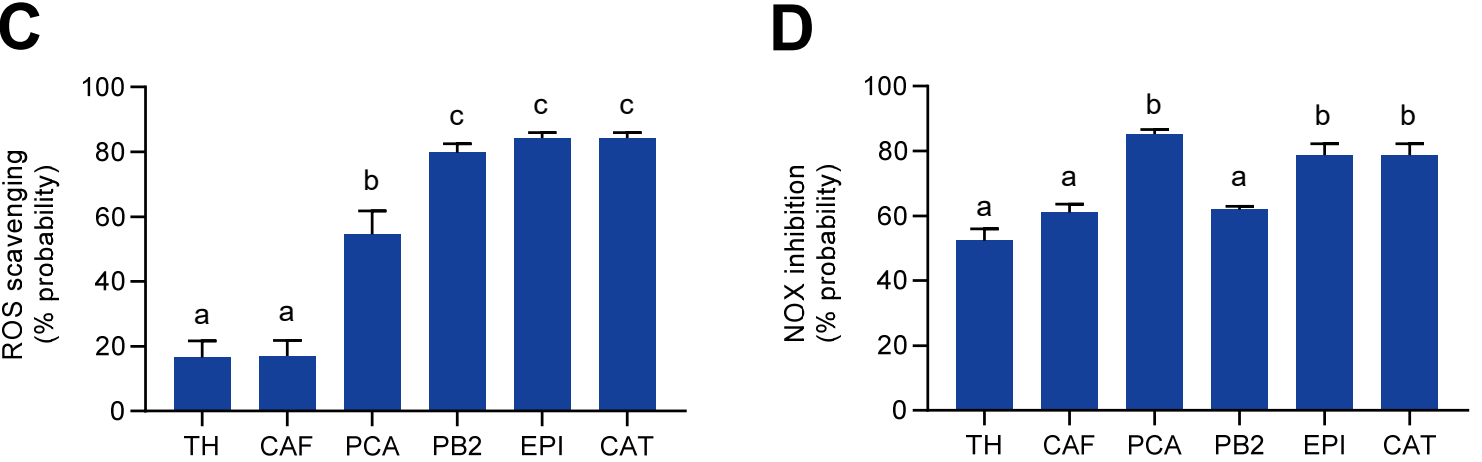

Figure 1. Chemical structure of the main phytochemicals found in the cocoa shell (A), their predicted bioavailability (B), and their potential to scavenge ROS (C), and inhibit NADPH oxidase (NOX) (D). The results are expressed as mean \pm SD $(n=3)$. Bars with different letters significantly $(p<0.05)$ differ according to ANOVA and Tukey's multiple range test.

3.3. Inflammatory Signaling Cascades, $T N F-\alpha, N F-\kappa B$, and JNK Are Regulated by the Phenolic Compounds Present in the Cocoa Shell

The probability of phytochemicals from the cocoa shell to modulate immunostimulation (Figure 2A) was significantly higher $(p<0.05)$ in methylxanthines than in the phenolic compounds. In contrast, Figure 2B shows that phenolic compounds (PCA, PB2, EPI, and CAT) exhibited higher $(p<0.05)$ TNF- $\alpha$ inhibitory potential $(63.1 \%)$ than methylxanthines (TH, 24.1\% and CAF, 30.9\%). Regarding the inhibition of the NF-KB (Figure 2C), EPI and CAT were the compounds that showed the highest inhibition capacity $(61.8 \%)$, followed by PB2 (55.1\%) and PCA (32.1\%). All compounds were able to inhibit JNK (30.0-52.8\%) (Figure 2D). TNF- $\alpha$ is one of the primary cytokines that stimulate inflammation. TNF- $\alpha$ can be inhibited by natural compounds, such as phenolic compounds, terpenes, and alkaloids, since these phytochemicals can interfere with pro-inflammatory mediators and upstream targets, such as NF-kB, JNK, and other signaling molecules, involved in TNF- $\alpha$ expression [19]. Moreover, since NF- $\kappa B$ and JNK are implicated in regulating the expression of many genes involved in obesity and diabetes-triggered inflammation, they represent a target in the search for new chemopreventive active compounds. In this regard, phenolic compounds may be promising due to their inhibitory effects on NF- $\mathrm{kB}$ and JNK activation. 
A

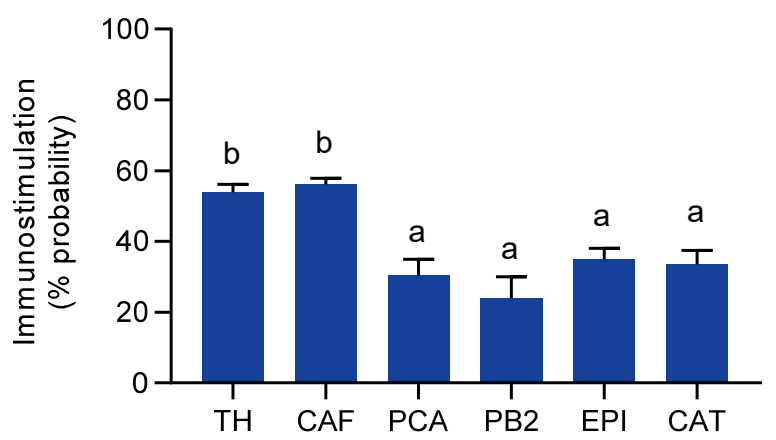

C

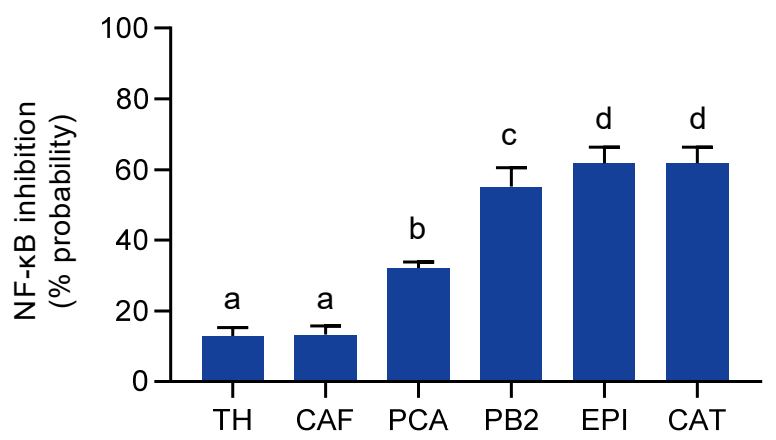

B

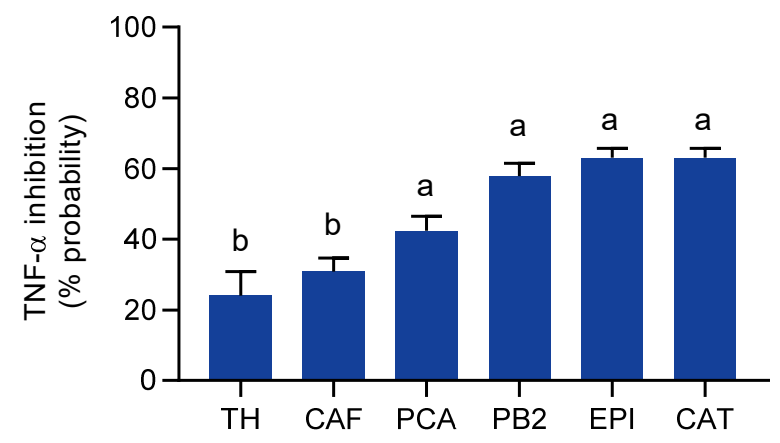

D

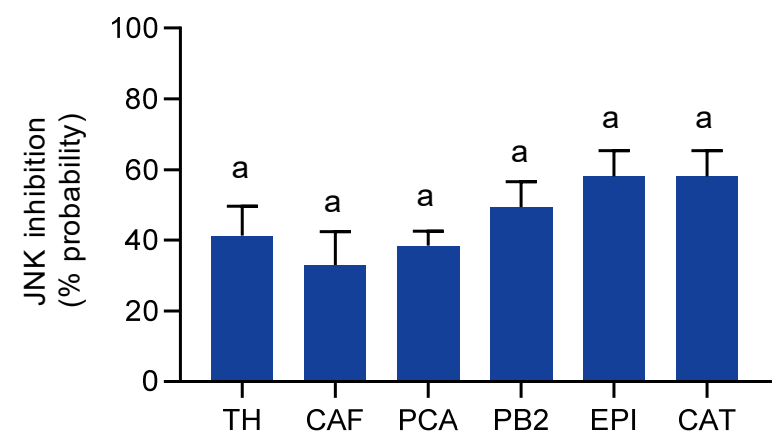

Figure 2. Potential effect of the phytochemicals from the cocoa shell on the modulation of immunostimulation (A), TNF- $\alpha$ production $(\mathbf{B})$, and NF- $\kappa B(\mathbf{C})$ and JNK (D) signaling cascades activation. The results are expressed as mean $\pm \mathrm{SD}(n=3)$. Bars with different letters significantly $(p<0.05)$ differ according to ANOVA and Tukey's multiple range test.

\subsection{Protocatechuic Acid Is the Main Contributor to Glucose and Lipid Metabolism Regulation}

PCA was significantly more likely to inhibit the fatty acid synthase (FASN) (92.3\%, $p<0.05)$ and, in general, modulate lipid metabolism $(71.0 \%, p<0.05)$ than the other phytochemicals found in the cocoa shell (Figure 3A,B). Studies in animal models have shown an improvement in lipid profile after PCA consumption [20]. Methylxanthines, especially caffeine, showed a significant probability to regulate lipid metabolism $(44.6-62.7 \%, p<0.05)$ but with a lower probability of inhibiting FASN $(24.9-33.5 \%, p<0.05)$.

The main mechanism of action of methylxanthines in the regulation of lipid metabolism is through suppression of adipogenesis and stimulation of thermogenesis and lipolysis [21-23]. PI3K-AKT pathway has been reported as a target to reverse insulin resistance. The probability of activating AKT (Figure $3 \mathrm{C})$ is higher $(p<0.05)$ in phenolic compounds (57.3-75.3\%) than in methylxanthines (33.3-36.6\%). PCA showed the greatest probability for activating AKT. Similarly, PCA exhibits insulin-mimicking properties by activating INSR signaling, reversing INS-1 serine phosphorylation, and activating PI3K/AKT and AMPK signaling pathways, and subsequently increasing GLUT4 translocation and glucose uptake in adipocytes [24]. Moreover, PCA has been shown to reduce glucose-6-phosphatase expression and activity and to promote glucose uptake in hepatocytes and myoblasts [25]. Hence, PCA seems to be a possible candidate in preventing metabolic disorders associated with lipid and glucose metabolism dysregulations and insulin resistance. 
A

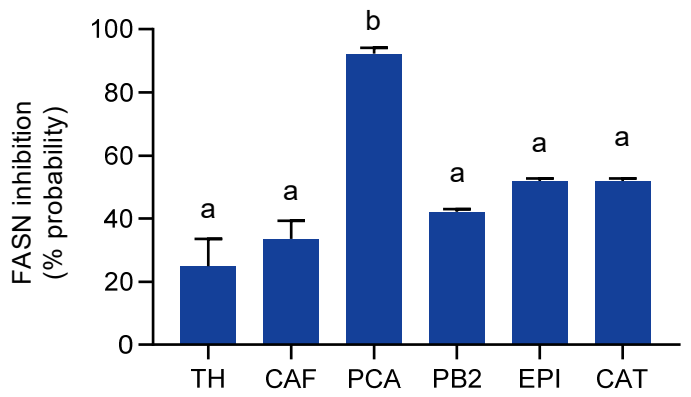

C

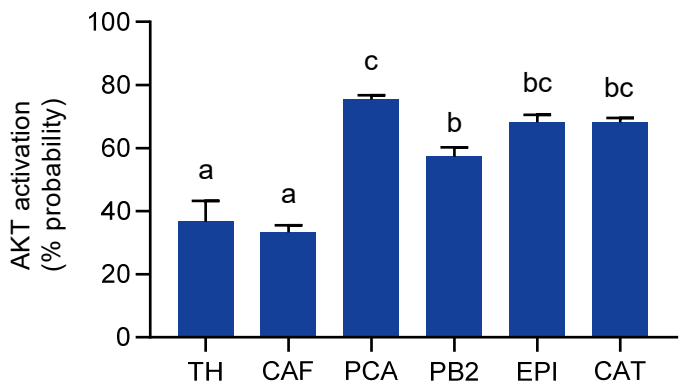

B

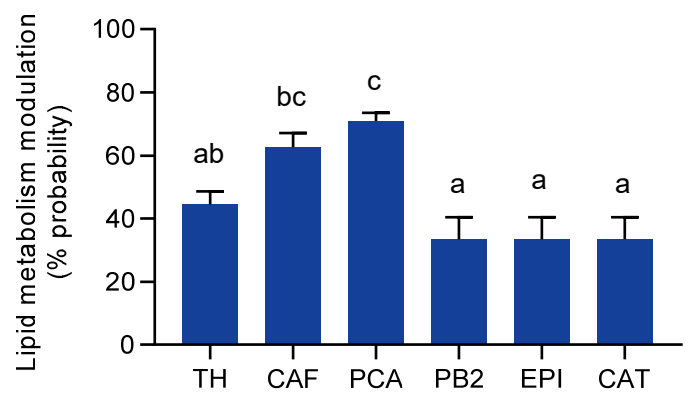

D

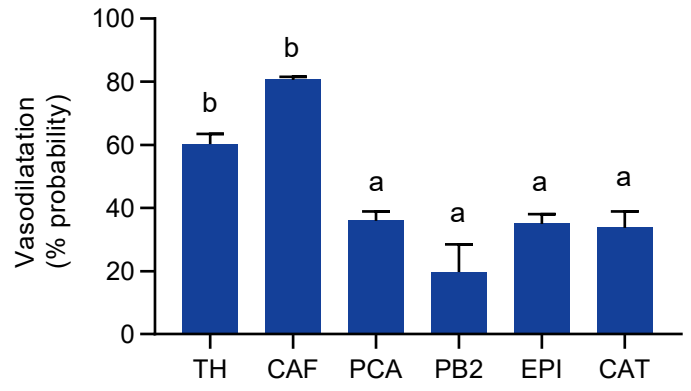

Figure 3. Regulatory properties of the phytochemicals from the cocoa shell on the inhibition of FASN (A), the modulation of lipid metabolism (B), the activation of protein kinase B (AKT) (C), and the stimulation of vasodilatation (D). The results are expressed as mean $\pm \mathrm{SD}(n=3)$. Bars with different letters significantly $(p<0.05)$ differ according to ANOVA and Tukey's multiple range test.

\subsection{Methylxanthines, Theobromine and Caffeine, Present Vasoactive Properties}

The methylxanthines found in the cocoa shell, especially caffeine $(80.6 \%, p<0.05)$, presented a high probability for vasodilatation (Figure 3D). Literature has evidenced that methylxanthines exhibit vasoactive properties [26,27]. Caffeine can regulate vascular function through equilibrium between its endothelium-dependent vasodilator ability, mediated by the endogenous NO production and its vasoconstrictive effect as an adenosine receptor antagonist [26]. Notwithstanding the potential vasodilatation activity of theobromine $(60.2 \%)$, it has only been reported to increase fasting and postprandial arterial diameter and decrease augmentation index in obese subjects, although not improving the endothelial function [27].

3.6. Cocoa Shell Phytochemicals Regulate Key Signaling Pathways Associated with the Prevention of Metabolic Syndrome

The phytochemicals present in the cocoa shell regulate key signal pathways associated with preventing metabolic syndrome (Figure 4A,B). Of particular interest is the prediction of these cocoa shell compounds and the possible regulation of pathways related to nonalcoholic fatty liver disease and insulin resistance and PI3K-AKT signaling pathways, as well as those related to lipid metabolism, adaptive thermogenesis, adipocytokine signaling, and cAMP signaling pathway, being key markers in the prevention of metabolic syndrome. These compounds also showed a significant relation with longevity regulating pathways, maybe due to the possible regulation observed in response to oxidative stress and mTOR pathways, closely related to cellular aging [28]. In general, it is observed that the phytochemicals from the cocoa shell can modulate the main genes associated with metabolic syndrome and its complications. Results demonstrate that both methylxanthines and phenolic compounds exhibit biological effects following different molecular mechanisms. 

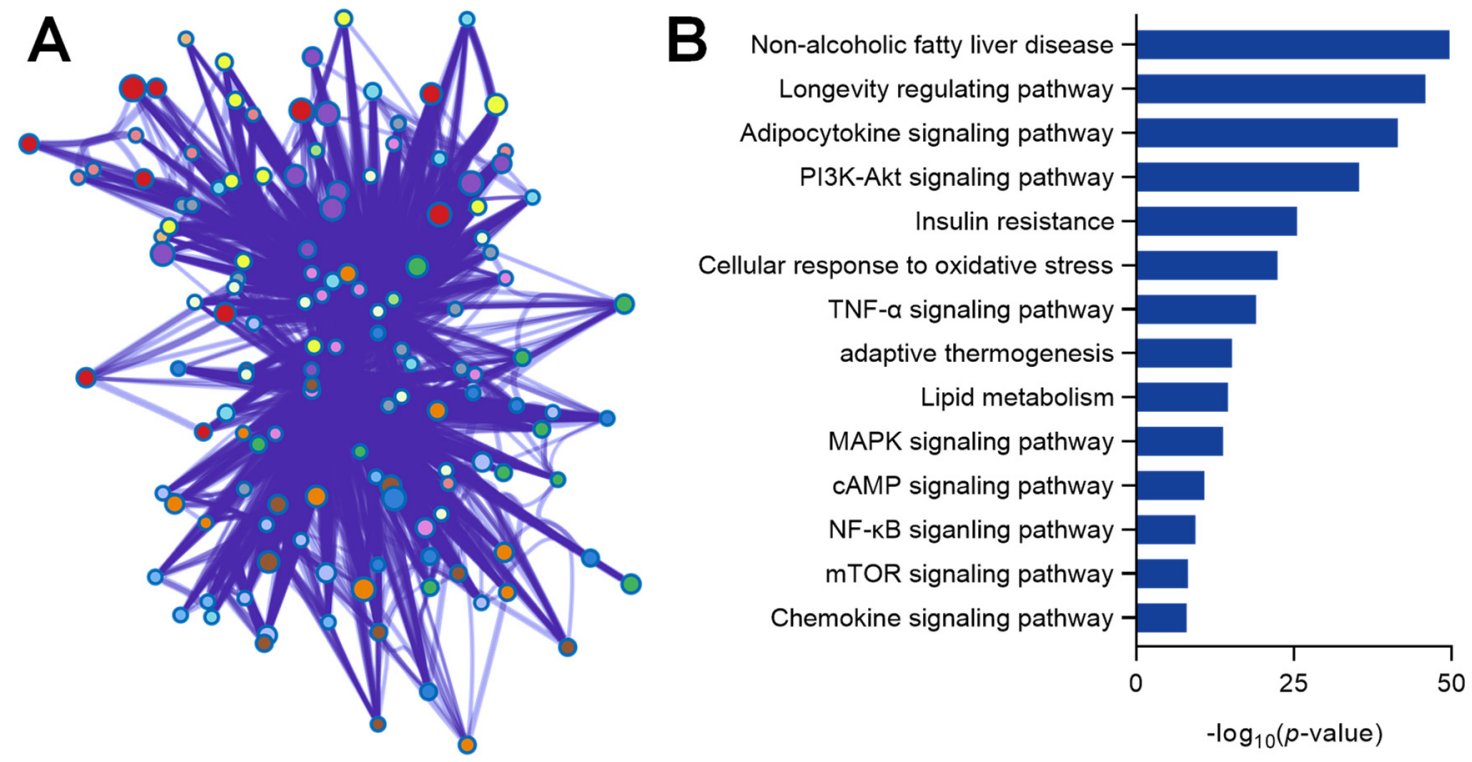

Figure 4. Protein-protein interaction networks built with Metascape from the most significant target genes associated with metabolic syndrome potentially modulated by the phytochemicals found in the cocoa shell (A) and the KEGG pathways associated with those proteins obtained by the enrichment analysis (B).

Therefore, using the cocoa shell to produce active ingredients focused on preventing chronic metabolic diseases will serve as a multimechanistic chemopreventive treatment. Our integrated network pharmacology analysis presents new insights into the biological activity and molecular mechanisms of the cocoa shell's main bioactive components, thereby establishing this by-product as a prospective agent for more in vitro and in vivo investigation, especially focused on the evaluation of its use for treating disorders involving oxidative stress, inflammation, glucose and lipid metabolism, and insulin resistance.

\section{Conclusions}

Results derived from this first integrated network pharmacology study demonstrated that cocoa shell phytochemicals could serve as modulators of key biological processes and signaling cascades associated with the prevention of metabolic syndrome. The revalorization of the cocoa shell as a nutraceutical could result in a product used for the dietetic prevention of chronic metabolic disorders. Upcoming in vivo and clinical investigations are required to validate this potential nutraceutical and healthy ingredient's effects and mechanisms.

Author Contributions: Conceptualization, M.R.-H.; methodology, M.R.-H.; formal analysis, M.R.-H., S.C. and C.B.; investigation, M.R.-H., S.C. and C.B.; data curation, M.R.-H.; writing-original draft preparation, M.R.-H., S.C. and C.B.; writing-review and editing, M.R.-H., S.C., C.B., S.M.A. and M.A.M.-C.; visualization, M.R.-H.; supervision, M.R.-H. and M.A.M.-C.; funding acquisition, S.M.A. and M.A.M.-C. All authors have read and agreed to the published version of the manuscript.

Funding: This research was funded by the Spanish Ministry of Science and Innovation, SUSCOFFEE (grant number AGL2014-57239-R), COCARDIOLAC (grant number RTI 2018-097504-B-I00) projects, and M. A. Martín-Cabrejas thanks to the Excellence Line for University Teaching Staff within the Multiannual Agreement between the Community of Madrid and the UAM (2019-2023). M. Rebollo-Hernanz thanks to the Ministry of Universities for his predoctoral fellowship (grant number FPU15/04238) and Margarita Salas Contract (CA1/RSUE/2021-00656). C. Braojos received funding from the Youth Guarantee Grant of the Community of Madrid for her predoctoral fellowship (PEJD-2019-PRE/BIO-16499).

Institutional Review Board Statement: Not applicable. 
Informed Consent Statement: Not applicable.

Data Availability Statement: The data presented in this study are available from the corresponding author on reasonable request.

Conflicts of Interest: The authors declare no conflict of interest.

\section{References}

1. Wang, H.H.; Lee, D.K.; Liu, M.; Portincasa, P.; Wang, D.Q.H. Novel insights into the pathogenesis and management of the metabolic syndrome. Pediatr. Gastroenterol. Hepatol. Nutr. 2020, 23, 189-230. [CrossRef] [PubMed]

2. Lee, E.G.; Choi, J.H.; Kim, K.E.; Kim, J.H. Effects of a walking program on self-management and risk factors of metabolic syndrome in older Korean adults. J. Phys. Ther. Sci. 2014, 26, 105-109. [CrossRef] [PubMed]

3. de la Iglesia, R.; Loria-Kohen, V.; Zulet, M.; Martinez, J.; Reglero, G.; Ramirez de Molina, A. Dietary Strategies Implicated in the Prevention and Treatment of Metabolic Syndrome. Int. J. Mol. Sci. 2016, 17, 1877. [CrossRef]

4. Eslamparast, T.; Tandon, P.; Raman, M. Dietary Composition Independent of Weight Loss in the Management of Non-Alcoholic Fatty Liver Disease. Nutrients 2017, 9, 800. [CrossRef] [PubMed]

5. Grillo, G.; Boffa, L.; Binello, A.; Mantegna, S.; Cravotto, G.; Chemat, F.; Dizhbite, T.; Lauberte, L.; Telysheva, G. Cocoa bean shell waste valorisation; extraction from lab to pilot-scale cavitational reactors. Food Res. Int. 2019, 115, 200-208. [CrossRef]

6. Hashimoto, J.C.; Lima, J.C.; Celeghini, R.M.S.; Nogueira, A.B.; Efraim, P.; Poppi, R.J.; Pallone, J.A.L. Quality Control of Commercial Cocoa Beans (Theobroma cacao L.) by Near-infrared Spectroscopy. Food Anal. Methods 2018, 11, 1510-1517. [CrossRef]

7. Okiyama, D.C.G.; Navarro, S.L.B.; Rodrigues, C.E.C. Cocoa shell and its compounds: Applications in the food industry. Trends Food Sci. Technol. 2017, 63, 103-112. [CrossRef]

8. Rojo-Poveda, O.; Barbosa-Pereira, L.; Zeppa, G.; Stévigny, C. Cocoa bean shell—a by-product with nutritional properties and biofunctional potential. Nutrients 2020, 12, 1123. [CrossRef] [PubMed]

9. Rebollo-Hernanz, M.; Zhang, Q.; Aguilera, Y.; Martín-Cabrejas, M.A.; de Mejia, E.G. Relationship of the phytochemicals from coffee and cocoa by-products with their potential to modulate biomarkers of metabolic syndrome in vitro. Antioxidants 2019, 8 , 279. [CrossRef] [PubMed]

10. Rebollo-Hernanz, M.; Zhang, Q.; Aguilera, Y.; Martín-Cabrejas, M.A.; de Mejia, E.G. Cocoa Shell Aqueous Phenolic Extract Preserves Mitochondrial Function and Insulin Sensitivity by Attenuating Inflammation between Macrophages and Adipocytes In Vitro. Mol. Nutr. Food Res. 2019, 63, 1801413. [CrossRef] [PubMed]

11. Hopkins, A.L. Network pharmacology. Nat. Biotechnol. 2007, 25, 1110-1111. [CrossRef] [PubMed]

12. Chandran, U.; Mehendale, N.; Patil, S.; Chaguturu, R.; Patwardhan, B. Network Pharmacology. In Innovative Approaches in Drug Discovery: Ethnopharmacology, Systems Biology and Holistic Targeting; Elsevier: Amsterdam, The Netherlands, 2017 ; pp. 127-164. ISBN 9780128018224.

13. Lagunin, A.; Stepanchikova, A.; Filimonov, D.; Poroikov, V. PASS: Prediction of activity spectra for biologically active substances. Bioinformatics 2000, 16, 747-748. [CrossRef] [PubMed]

14. Rebollo-Hernanz, M.; Cañas, S.; Taladrid, D.; Bartolomé, B.; Aguilera, Y.; Martin-Cabrejas, M.A. Extraction of phenolic compounds from cocoa shell: Modeling using response surface methodology and artificial neural networks. Sep. Purif. Technol. 2021, 270, 118779. [CrossRef]

15. Rein, M.J.; Renouf, M.; Cruz-Hernandez, C.; Actis-Goretta, L.; Thakkar, S.K.; da Silva Pinto, M. Bioavailability of bioactive food compounds: A challenging journey to bioefficacy. Br. J. Clin. Pharmacol. 2013, 75, 588-602. [CrossRef] [PubMed]

16. Rahman, M.M.; Rahaman, M.S.; Islam, M.R.; Rahman, F.; Mithi, F.M.; Alqahtani, T.; Almikhlafi, M.A.; Alghamdi, S.Q.; Alruwaili, A.S.; Hossain, M.S.; et al. Role of Phenolic Compounds in Human Disease: Current Knowledge and Future Prospects. Molecules 2022, 27, 233. [CrossRef]

17. Yousefian, M.; Shakour, N.; Hosseinzadeh, H.; Hayes, A.W.; Hadizadeh, F.; Karimi, G. The natural phenolic compounds as modulators of NADPH oxidases in hypertension. Phytomedicine 2019, 55, 200-213. [CrossRef] [PubMed]

18. Cañas, S.; Rebollo-Hernanz, M.; Aguilera, Y.; Benítez, V.; Braojos, C.; Arribas, S.M.; Martín-Cabrejas, M.A. Bioaccessibility of Phenolic Compounds from Cocoa Shell Subjected to In Vitro Digestion and Its Antioxidant Activity in Intestinal and Hepatic Cells. Med. Sci. Forum 2021, 2, 5. [CrossRef]

19. Paul, A.T.; Gohil, V.M.; Bhutani, K.K. Modulating TNF- $\alpha$ signaling with natural products. Drug Discov. Today 2006, 11, 725-732. [CrossRef] [PubMed]

20. Lobo, A.; Liu, Y.; Song, Y.; Liu, S.; Zhang, R.; Liang, H.; Xin, H. Effect of procyanidins on lipid metabolism and inflammation in rats exposed to alcohol and iron. Heliyon 2020, 6, e04847. [CrossRef]

21. Acheson, K.J.; Gremaud, G.; Meirim, I.; Montigon, F.; Krebs, Y.; Fay, L.B.; Gay, L.; Schneiter, P.; Schindler, C.; Tappy, L. Metabolic Effects of Caffeine in Humans: Lipid Oxidation or Futile Cycling? Am. J. Clin. Nutr. 2004, 79, 40-46. [CrossRef] [PubMed]

22. Zapata, F.J.; Rebollo-Hernanz, M.; Novakofski, J.E.; Nakamura, M.T.; de Mejia, E.G. Caffeine, but not other phytochemicals, in mate tea (Ilex paraguariensis St. Hilaire) attenuates high-fat-high-sucrose-diet-driven lipogenesis and body fat accumulation. J. Funct. Foods 2020, 64, 103646. [CrossRef]

23. Carrageta, D.F.; Dias, T.R.; Alves, M.G.; Oliveira, P.F.; Monteiro, M.P.; Silva, B.M. Anti-obesity potential of natural methylxanthines. J. Funct. Foods 2018, 43, 84-94. [CrossRef] 
24. Scazzocchio, B.; Varì, R.; Filesi, C.; Del Gaudio, I.; D'Archivio, M.; Santangelo, C.; Iacovelli, A.; Galvano, F.; Pluchinotta, F.R.; Giovannini, C.; et al. Protocatechuic acid activates key components of insulin signaling pathway mimicking insulin activity. Mol. Nutr. Food Res. 2015, 59, 1472-1481. [CrossRef] [PubMed]

25. Sheikh, Y.; Chanu, M.B.; Mondal, G.; Manna, P.; Chattoraj, A.; Chandra Deka, D.; Chandra Talukdar, N.; Chandra Borah, J. Procyanidin A2, an anti-diabetic condensed tannin extracted from: Wendlandia glabrata, reduces elevated G-6-Pase and mRNA levels in diabetic mice and increases glucose uptake in CC1 hepatocytes and C1C12 myoblast cells. RSC Adv. 2019, 9, 17211-17219. [CrossRef]

26. Umemura, T.; Ueda, K.; Nishioka, K.; Hidaka, T.; Takemoto, H.; Nakamura, S.; Jitsuiki, D.; Soga, J.; Goto, C.; Chayama, K.; et al. Effects of Acute Administration of Caffeine on Vascular Function. Am. J. Cardiol. 2006, 98, 1538-1541. [CrossRef] [PubMed]

27. Smolders, L.; Mensink, R.P.; Boekschoten, M.V.; de Ridder, R.J.J.; Plat, J. Theobromine does not affect postprandial lipid metabolism and duodenal gene expression, but has unfavorable effects on postprandial glucose and insulin responses in humans. Clin. Nutr. 2018, 37, 719-727. [CrossRef]

28. Rebollo-Hernanz, M.; Aguilera, Y.; Martin-Cabrejas, M.A.; Gonzalez de Mejia, E. Phytochemicals from the Cocoa Shell Modulate Mitochondrial Function, Lipid and Glucose Metabolism in Hepatocytes via Activation of FGF21/ERK, AKT, and mTOR Pathways. Antioxidants 2022, 11, 136. [CrossRef] [PubMed] 